\title{
DEFLECTION OF PLATES BY USING PRINCIPLE OF QUASI WORK
}

\author{
Mahavir Singh $^{\text {a, *, I.K. Pandita }}{ }^{\text {a }}$, S.K. Kheer ${ }^{\text {b }}$ \\ ${ }^{a}$ Mech. Engg. Dept.; N. I. T. Srinagar, J\&K-190006; India ; vir.singh@hotmail.com, ikpandita@rediffmail.com \\ ${ }^{b}$ Mech. Engg. Dept.(PWD); Shalteng, Srinagar-190017; sajsurajsaj@gmail.com
}

Received: 05.10.2016 / Accepted: 10.10.2016 / Revised: 20.11.2016 / Available online: 15.12.2016

DOI: $10.1515 /$ jaes-2016-0013

KEY WORDS: Deflection, Plates, Reference system, Topological Similarity, Principle of Quasi Work, Structural Analysis

\begin{abstract}
:
A new methodology based on Principle of Quasi Work is used for calculating the deflections in plates. The basis of this methodology is concept of topologically similar systems. Present method uses a priory known solution for deflection of a simply supported plate for arriving at the deflection of any other topologically similar plate with different loading and boundary conditions. This priory known solution is herein referred to as reference equation. Present methodology is easy as deflections are obtained mostly by elementary mathematics for point loads and for other loads by integration that's integrant is reference equation multiplied by the equation of load. In the present methodology solution of fourth order partial differential equation in two independent variables as used in lengthy and not so easy conventional method is bypassed.
\end{abstract}

\section{INTRODUCTION}

Various methods and techniques are used for analysing and solving different structural mechanics problem. Generally most common methods used (Akin, 1994; Zienkiewicz and Taylor, 1989; Rao, 1989) are based on finite element method or formulations that use stiffness method or force method or combination of both. All these methods are applicable to single structural system. Structural problems have also been solved by transporting these in other (Electrical field, etc.) which requires one to have knowledge of other fields of science also. To overcome this disadvantage PQW which connects two topologically similar structures was developed by (Panditta, 1996). In this paper, PQW is applied to topological similar plates for finding the deflections. Two systems are topological similar when their number of nodes and nodal connectivity are same as given by (Panditta et al., 1999) and (Pandita and Wani, 2012). PQW has been successfully used with advantage for obtaining deflection of bars, shafts and beams without resorting to internal forces/moments by (Pandita and Wani, 2012). PQW is advantageously used for obtaining redundant reactions of beams (Pandita et al., 2010). A quick and simplified method for obtaining nodal deflections of an indeterminate truss using PQW was developed (Pandita, 2010). PQW was also used (Singh et al., 2016) for the improvement of water distribution networks analysis by topological similarity. In the present methodology concept of Reference plate is developed. Deflection of other topological similar determinate/ indeterminate plates with different loading and boundary conditions is calculated with the help of the reference equation (deflection equation of reference plate).

\subsection{Principle of Quasi Work (PQW)}

Principle of quasi work was first proved by (Panditta, 1996) and subsequently stated by (Panditta et al., 1999). According to this principle quasi work, 'Wmn', done by external forces of one system (say ' $m$ ') while going through the corresponding displacements of the other topologically similar system (say 'n') is equal to the quasi strain energy, 'Umn', due to internal forces

* Corresponding author: e-mail: vir.singh@hotmail.com 
of former system (' $m$ ') while going through corresponding deformations of the latter system (' $n$ '). In mathematical terms it can be stated as $W_{m n}=U_{m n}$. In a similar way, this principle is applied to plates and quasi work for two equivalent plates will be equated, as no internal forces equations are used in plates Accordingly, quasi work, ' $W_{m n}$ ', done by external forces of one system (say ' $m$ ') while going through the corresponding displacements of the other topologically similar system (say ' $n$ ') is equal to the work done, ' $W_{n m}$ ', due to external forces of former system (' $n$ ') while going through corresponding deformations of the latter system ' $m$ '.

Mathematically:

$$
W_{m n}=W_{n m}
$$

In this principle, word 'corresponding' needs clarification. For example, take two Plates 'ABCD' and 'EFGH' (Figure 1) having lengths and breadth 'L1', 'B1' and 'L2', 'B2'. In these two plates corner ' $\mathrm{A}$ ' corresponds to corner ' $\mathrm{E}$ ' and corner ' $\mathrm{B}$ ' to corner ' $F$ '.
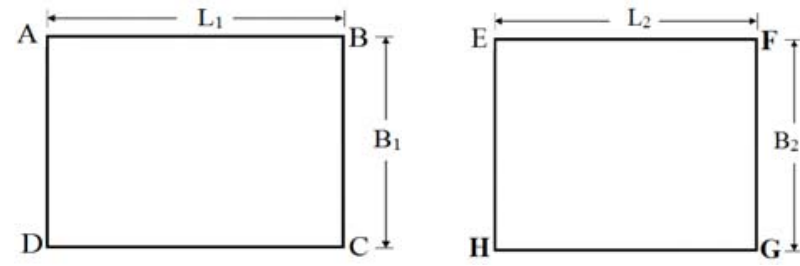

Figure 1. Rectangular Plates ABCD \& EFGH with length $\mathrm{L}_{1}, \mathrm{~L}_{2}$ and breadth $\mathrm{B}_{1}, \mathrm{~B}_{2}$ respectively

In such cases, one has to resort to mapping in the two structural domains. For example, if a transverse load is acting at $0.75 \mathrm{~L} 2$ from corner ' $\mathrm{A}$ ' in Plate 'ABCD' then its corresponding point in Plate 'EFGH' will be 0.75L2 from end 'E'. Similarly we can find the point on the other edges of the plates.

\subsection{Topological Similar Structures}

In the statement of PQW, topology for discrete structural models specifies a unique set of nodes and their interconnectivity in a system. For TSS, the physical/material properties and the constitutive relations of branch elements (connecting different nodes) are immaterial. Boundary conditions and external loading on the system are not included in the concept of topology. Hence, for a given structural system an infinite number of TSS can be generated by varying a branch/element parameter from limiting values of zero/infinity (making such load paths vanish/rigid) and also by substituting one type of element by another type of element (e.g., replacing spring by a damper). This concept of TSS was well explained by (Pandita et al., 2010).

\section{REFERENCE PLATE}

The concept of reference beam which was used (Pandita et al., 2010) to find the reactions of other topologically similar beams. Now in a similar way, here reference Plate (figure 2) has been taken whose deflection is given. This reference plate is a simply supported rectangular plate of length $a$ and breadth $b$ with point load $P$ at a distance of $x=\xi$ and $y=\eta$

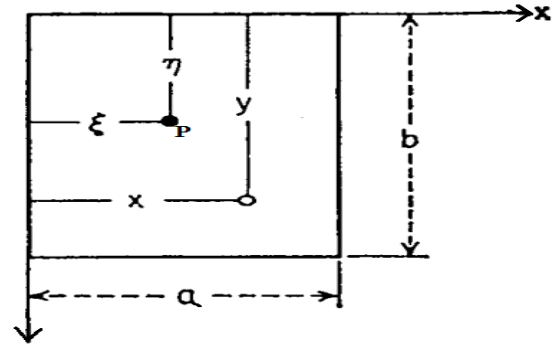

Figure 2. Simply supported rectangular Plate with point load $P$ : system 2

Now consider the Deflection equation given (Timoshenko and Woinowsky-Krieger, 1959) as a reference Equation and this equation is further used for calculating Deflection of Plates at any point of the plate with different boundary conditions. For the given Figure 2, Deflection and its derivatives are:

$$
[w(x . y)]_{2}=\frac{4 P}{a b D \pi^{4}} \sum_{m=1}^{\infty} \sum_{n=1}^{\infty} \frac{\sin \frac{m \pi \xi}{a} \sin \frac{n \pi \eta}{b}}{\left(\frac{m^{2}}{a^{2}}+\frac{n^{2}}{b^{2}}\right)^{2}} \sin \frac{m \pi x}{a} \sin \frac{n \pi y}{b}
$$

$$
\frac{\partial w}{\partial x}=\frac{4 P}{a^{2} b D \pi^{3}} \sum_{m=1}^{\infty} \sum_{n=1}^{\infty} \frac{\sin \frac{m \pi \xi}{a} \sin \frac{n \pi \eta}{b}}{\left(\frac{m^{2}}{a^{2}}+\frac{n^{2}}{b^{2}}\right)^{2}} m \cos \frac{m \pi x}{a} \sin \frac{n \pi y}{b}
$$




\subsection{Solution using Reference System}

Example 2.1.1: Simply supported rectangular plate with uniformly distributed (figure 3).

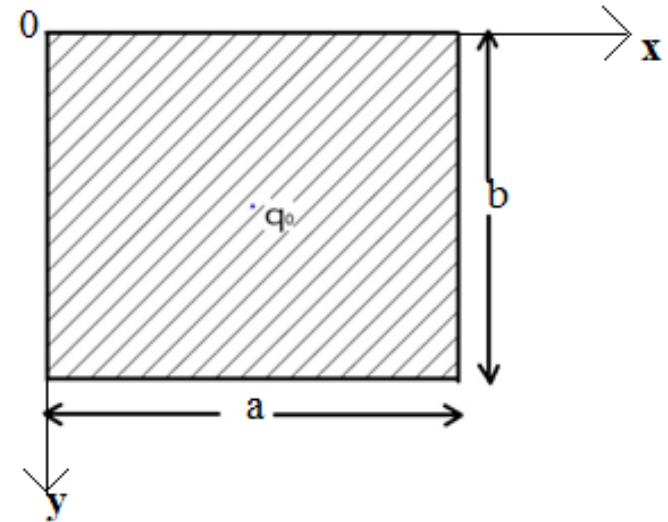

Figure 3. Simply supported Plate with uniformly distributed load: system 1

For the given problem quasi work done is given by:

Quasi work done:

$W_{12}=\int_{0}^{a} \int_{0}^{b}\left[q_{0}\right]_{1}[w(x, y)]_{2} d x d y$

where: $q_{0}$ is the intensity of the uniformly distributed load.

Substitute Eq. (2), we get:

$W_{12}=\frac{q_{0} 4 P}{a b D \pi^{4}} \sum_{m=1}^{\infty} \sum_{n=1}^{\infty} \frac{\sin \frac{m \pi \xi}{a} \sin \frac{n \pi \eta}{b}}{\left(\frac{m^{2}}{a^{2}}+\frac{n^{2}}{b^{2}}\right)^{2}} \int_{0}^{b} \int_{0}^{b} \sin \frac{m \pi x}{a} \sin \frac{n \pi y}{b} d x d y$

$W_{12}=\frac{16 q_{0} P}{\pi^{6} D} \sum_{m=1}^{\infty} \sum_{n=1}^{\infty} \frac{\sin \frac{m \pi \xi}{a} \sin \frac{n \pi \eta}{b}}{m n\left(\frac{m^{2}}{a^{2}}+\frac{n^{2}}{b^{2}}\right)^{2}}$

Similarly, $W_{21}$ is given by:

$W_{21}=[P]_{2}[w(\xi, \eta)]_{1}=W_{12}$

Using PQW, equations (7) and (8) yield:

$[w(\xi, \eta)]_{1}=\frac{16 q_{0}}{\pi^{6} D} \sum_{m=1}^{\infty} \sum_{n=1}^{\infty} \frac{\sin \frac{m \pi \xi}{a} \sin \frac{n \pi \eta}{b}}{m n\left(\frac{m^{2}}{a^{2}}+\frac{n^{2}}{b^{2}}\right)^{2}}$
This expression is same as obtained by conventional method (Timoshenko and Woinowsky-Krieger, 1959).

Example 2.1.2: Rectangular Plate simply supported along the edges and loaded by moments distributed along the edges $\mathrm{x}=0$ and $\mathrm{x}=\mathrm{a}$ (figure 4 ).

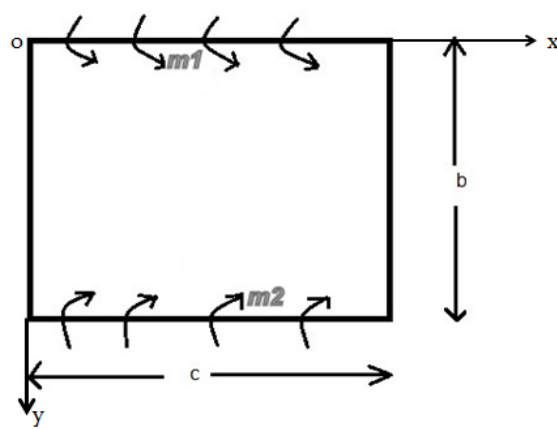

Figure 4. Simply supported rectangular Plate with bending load along two opposite edges

Using equation (2) and (3), quasi work is given by:

$W_{12}=\left.m_{1} \int_{0}^{a} \frac{\partial w}{\partial y}\right|_{y=0} d x-\left.m_{2} \int_{0}^{a} \frac{\partial w}{\partial y}\right|_{y=b} d x$

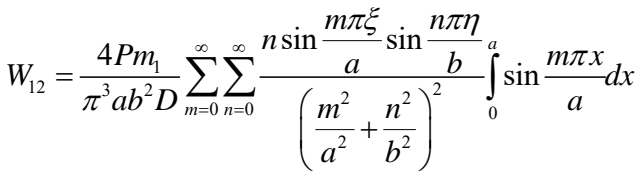

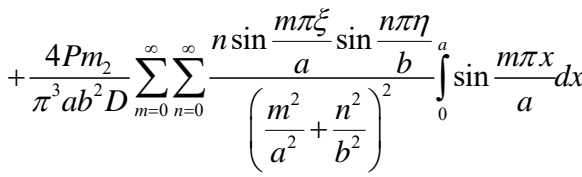

Let us take symmetrical case in which:

$\left|m_{1}\right|=\left|m_{2}\right|=M_{0}$

$W_{12}=\frac{8 P M_{0}}{\pi^{3} a b^{2} D} \sum_{m=0}^{\infty} \sum_{n=0}^{\infty} \frac{n \sin \frac{m \pi \xi}{a} \sin \frac{n \pi \eta}{b}}{\left(\frac{m^{2}}{a^{2}}+\frac{n^{2}}{b^{2}}\right)^{2}} \int_{0}^{a} \sin \frac{m \pi x}{a} d x$

$W_{12}=\frac{16 P M_{0}}{\pi^{4} b^{2} D} \sum_{m=0}^{\infty} \sum_{n=0}^{\infty} \frac{n \sin \frac{m \pi \xi}{a} \sin \frac{n \pi \eta}{b}}{m\left(\frac{m^{2}}{a^{2}}+\frac{n^{2}}{b^{2}}\right)^{2}}$

Similarly, using PQW $W_{21}$ is:

$$
W_{21}=[P]_{2}[w(\xi, \eta)]_{1}=W_{12}
$$

Using PQW equations (14) and (15) yield: 


$$
[w(\xi, \eta)]_{1}=\frac{16 M_{0}}{\pi^{4} b^{2} D} \sum_{m=0}^{\infty} \sum_{n=0}^{\infty} \frac{n \sin \frac{m \pi \xi}{a} \sin \frac{n \pi \eta}{b}}{m\left(\frac{m^{2}}{a^{2}}+\frac{n^{2}}{b^{2}}\right)^{2}}
$$

Maximum deflection obtained by above equation and as obtained by conventional method is compared. Maximum deflection is at the centre of rectangular plate i.e.:

$$
\text { At } \xi=\frac{a}{2} \text { and } \eta=\frac{b}{2}
$$

Summation of first three terms of the series $(m, n)=(1,1)$, $(1,3),(3,1)$ and $(3,3)$ in the above equation and the first two terms of the deflection equation (Timoshenko and WoinowskyKrieger, 1959) are given in Table 1.

$w=\frac{2 M_{0} a^{2}}{\pi^{3} D} \sum_{m=1,3,5 . .}^{\infty} \frac{1}{m^{3}} \frac{\alpha_{m} \tanh \alpha_{m}}{\cosh \alpha_{m}} \sin \frac{m \pi x}{a}$

For the ratio $b / a=1$, deflection by both methods is as under (table 1):

\begin{tabular}{|c|c|c|c|c|}
\hline \multicolumn{5}{|c|}{ Current Method } \\
\hline $\boldsymbol{m}$ & 1 & 1 & 1 & 3 \\
\hline $\boldsymbol{n}$ & 1 & 3 & 5 & 1 \\
\hline $\boldsymbol{W}_{\boldsymbol{m} n}$ & 0.0410 & -0.0049 & 0.0012 & -0.0005 \\
\hline $\begin{array}{c}\text { Total } \\
\boldsymbol{W}_{\boldsymbol{m} \boldsymbol{n}}\end{array}$ & 0.0410 & 0.0361 & 0.0373 & 0.0368 \\
\hline $\mathrm{W}=\Sigma \mathrm{W}_{\mathrm{mn}}=0.0368 \mathrm{M}_{\mathrm{o}} \mathrm{b}^{2} / \mathrm{D}$ which is same as (Timoshenko and \\
Woinowsky-Krieger, 1959) \\
\hline
\end{tabular}

Table 1. Deflection value by PQW method and conventional method when ratio $b / a=1$

Similarly for different b/a ratio of plate, deflection by both the methods is given in tabular form as below (table 2):

\begin{tabular}{|l|l|l|l|l|}
\hline $\mathbf{b} / \mathbf{a}$ & 0.5 & 1.0 & 1.5 & 2.0 \\
\hline$W(\mathbf{P Q W})$ & $\begin{array}{l}0.0964 \mathrm{M}_{0} \\
\mathrm{~b}^{2} / \mathrm{D}\end{array}$ & $\begin{array}{l}0.0368 \mathrm{M}_{0} \\
\mathrm{a}^{2} / \mathrm{D}\end{array}$ & $\begin{array}{l}0.0280 \mathrm{M}_{0} \\
\mathrm{a}^{2} / \mathrm{D}\end{array}$ & $\begin{array}{l}0.0174 \mathrm{M}_{0} \\
\mathrm{a}^{2} / \mathrm{D}\end{array}$ \\
\hline $\begin{array}{l}W \\
(\mathbf{1 0 )})\end{array}$ & $\begin{array}{l}0.0964 \mathrm{M}_{0} \\
\mathrm{~b}^{2} / \mathrm{D}\end{array}$ & $\begin{array}{l}0.0368 \mathrm{M}_{0} \\
\mathrm{a}^{2} / \mathrm{D}\end{array}$ & $\begin{array}{l}0.0280 \mathrm{M}_{0} \\
\mathrm{a}^{2} / \mathrm{D}\end{array}$ & $\begin{array}{l}0.0174 \mathrm{M}_{0} \\
\mathrm{a}^{2} / \mathrm{D}\end{array}$ \\
\hline
\end{tabular}

Table 2. Deflection value by PQW method and conventional method at different $b / a$ ratio

\section{CONCLUSION}

Using PQW, it is easy to find deflections of Plates because of following reasons:

I. PQW is an easy alternative method because there is no need to solve the fourth order partial differential equation in two independent variables.
II. With the help of a given equation of deflection of Reference Plate, the solution for other plates of same class can be calculated easily by PQW method.

III. As solution of reference plate is used for calculating the deflection of other plates of same class with different loading and boundary conditions, it is possible to develop an interactive graphic general purpose computer package for this purpose.

IV. The concepts of virtual force and complementary energy do not exist in PQW as both the systems are real. Hence, no additional effort is needed for learning.

\section{REFERENCES}

Akin, J.E., 1994. "Finite Elements for Analysis and Design", Academic Press, London.

Zienkiewicz, O. C. and Taylor, R. L., 1989. "The Finite Elements Method", McGraw Hill Book Co.

Rao, S. S., 1989. "The Finite Element Method in Engineering", Pergamon Press.

Panditta, I. K.. 1996. "Some Studies on Computer Aided Model Based Design,"Ph.D. Dissertation, Indian Institute of Technology, Bombay, India.

Panditta, I. K., Shimpi, R. P., and Prasad, K. S. R. K. 1999. “On the Theory of Discrete Model Analyses and Design,"International Journal of Solids and Structures, Vol. 36, No. 16, pp. 2443-2462. DOI: 10.1016/S0020-7683(98)00066-3.

Pandita, I.K., Wani, M.M. 2012, "Deflection of structures using Principle of Quasi Work", International Journal of Aerospace Sciences, DOI: 10.5923/ j.aerospace.20120105.01.

Pandita, I.K., Ambardhar, R. and Dembi, N.J. 2010, "Redundant Reactions of Indeterminate Beams by Principle of Quasi Work", AIAA journal, DOI: 10.2514/1.42470.

Panditta, Inder Krishen, 2012, "Derivative Theorems of the Principle of Quasi Work", International Journal of Aerospace Sciences, DOI: 10.5923/j.aerospace.20120103.02.

Singh, Mahavir, Kheer, S.K and Panditta, I.K., 2016, "Improvement of water distribution networks analysis by topological similarity", Alexandria Engineering Journal, Vol. 55, pp. 1375-1383. http://dx.doi.org/10.1016/j.aej.2016.04.023.

Timoshenko S.P. and S. Woinowsky-Krieger. 1959. "Theory of Plates and Shells", pp. 79-91, 105-111, 180-187, International Edition, second edition, Mc-Grath Hill Publications. 